\title{
José María Vargas Vila y la crítica: la construcción de un gran novelista malo
}

\section{Luis Henao Uribe/The Graduate Center, CUNY}

\section{Resumen}

José María Vargas Vila (1860 - 1933) fue uno de los escritores colombianos más leídos en Hispanoamérica a principios del siglo XX. Su éxito comercial, sus posiciones críticas frente a varios gobiernos americanos y a la moral católica, y su estilo combativo de las tradiciones del buen gusto del momento provocaron fuertes reacciones por parte de la crítica. Este artículo recoge y analiza algunas de las lecturas que se han hecho sobre Vargas Vila por más de un siglo, evidenciando los mecanismos discursivos que han sido usados para estigmatizarlo, pero también las contradicciones y enfrentamientos que su figura aún produce.

Palabras clave: Vargas Vila; Canon; Mercado; Valor literario; Éxito.

\begin{abstract}
José María Vargas Vila (1860 - 1933) was one of the most widely read Colombian writers in the Spanish speaking world at the beginning of the 20th century. His commercial success, his critical position against several national governments and Catholic morality and his combative style against the traditions of good taste provoked strong reactions among the literary critics. This article collects and analyzes some of the readings that have been done about Vargas Vila for more than a century, evidencing the discursive mechanisms that have been used to stigmatize him, but also the contradictions and confrontation that his figure still produces.
\end{abstract}

Keywords: Vargas Vila; Canon; Market; Literary Value; Success.
En 1911, el cura Pablo Ladrón de Guevara (1861-1935) publicó en Bilbao la segunda edición aumentada de Novelistas malos y buenos, un compendio donde se mencionan dos mil ciento quince novelistas, incluyendo algunos españoles -313 - , hispanoamericanos - 100 - , franceses - 1220-, entre otros. Escrita en Bogotá, el objetivo principal de la obra era servir como guía de criterios para que los sacerdotes recomendaran o no estas novelas a sus feligreses; criterios con valores distintos a aquellos promovidos por los editores y libreros. A diferencia de los diccionarios de literatura e historias literarias, "porque para ellos no hay una novela mala, como ella guste é interese" (Ladrón de Guevara 1911, 4), la intención era la de valorar estos textos por su posición moral y su capacidad de ofrecer buenas enseñanzas: "juzgamos y sentenciamos las novelas con arreglo al código de la ley de Dios" (4).

En el prólogo de Novelistas malos y buenos, bajo la pregunta “¿Cuál es la naturaleza de esta obra?”, se plantea la relación entre el juicio moral (en este caso específicamente religioso) y el juicio literario: "Pues si decimos de los autores malos que son sumamente artísticos y literarios, de un interés irresistible, los unos leerán las novelas malas, so color de literatura, y los otros, que no tienen consciencia y van en busca de entretenimientos, se tirarán al manjar venenoso que alabamos, riéndose de nuestros anatemas" (7). De acuerdo al proyecto de Ladrón de Guevara, un libro que contradijera los valores de la iglesia católica no debía ser leído y su estilo, sin importar cuál fuese, debía ser criticado: un libro 'malo' tenía que ser doblemente 'malo'. Dentro de esta lógica de lectura, no sorprende, entonces, encontrar una crítica a la vez moral y estilística bajo la entrada del escritor colombiano José María Vargas Vila (1860 - 1933):

...impío furibundo, desbocado blasfemo, desvergonzado calumniador, escritor deshonesto, clerófobo, hipócrita pertinazmente empeñado en que le compren por recto, sincero y amante de la verdad; egoísta con pretensiones de filántropo, y, finalmente, pedante, estrafalario hasta la locura, alardeando de políglota con impertinentes citas de lenguas extranjeras; inventor de palabras estrambóticas, $y$, en algunas obras, de una puntuación y ortografía en parte propia de perezosos é ignorantes; aunque, en honor de la verdad, él no la usa porque no sepa bien esa parte de la gramática, sino por hacerse singular”. (Ladrón de Guevara 1911, 447)

La cita de Ladrón de Guevara, enmarcada en esta obra específica con unas intenciones religiosas bien establecidas, 
ya presenta algunos de los elementos que la crítica literaria desplegó durante la carrera literaria de Vargas Vila y que reaparecen por mucho tiempo después de su muerte cuando se hace mención del autor en las páginas de las historias literarias, textos académicos y reseñas. José María Vargas Vila nació en Bogotá en 1860, pero su vida se vio marcada por múltiples desplazamientos: Tuvo que salir de Colombia a Venezuela por su militancia con el partido Liberal durante la revolución de fin de siglo y después vivió en Nueva York, Madrid, Roma y Barcelona — donde murió en 1933-. Vargas Vila fue un prolífico escritor con gran éxito comercial en Latinoamérica. Su actitud crítica hacia la tiranía lo llevó a enfrentarse con vehemencia en sus páginas a los gobiernos de Colombia, Venezuela y Estados Unidos, así como a la Iglesia Católica [1]. A nivel personal, es famosa su negativa de arrodillarse frente al Papa León XIII. Vargas Vila siempre ha sido una figura polémica, difícil de ubicar en el canon nacional colombiano y en el canon latinoamericano: es un autor constantemente caracterizado como 'malo' - y 'malo' desde distintas acepciones del término- lo que lo excluye de un lugar central en las letras nacionales; aun así, a lo largo de los años sigue reapareciendo como esa figura excéntrica, rara y estigmatizada, que nos permite evidenciar las tensiones y las lógicas de inclusión y exclusión del campo literario. Este artículo revisa y analiza algunas de las lecturas críticas que se han hecho sobre Vargas Vila por más de un siglo, evidenciando aquellos mecanismos discursivos que han sido usados para estigmatizarlo, pero también las contradicciones y enfrentamientos que su figura aún produce.

\section{Lecturas morales y apreciación estética: el germen de la crítica}

El libro de Alejandro Andrade Coello Vargas Vila. Ojeada crítica de sus obras: De "Aura o las violetas" a "El ritmo de la vida", publicado en Quito en 1912, es un testimonio de la recepción crítica de las obras de Vargas Vila por parte de sus contemporáneos. Partiendo de la admiración confesa que el autor ecuatoriano siente por las letras colombianas - “ $\mathrm{iOh}$ Colombia, tierra fecunda de las letras, Musa lozana que habitas la excelsa cumbre del Parnaso!" (Andrade Coello 1912, 3)-, establece una genealogía de grandes hombres y escritores colombianos desde Simón Bolívar, pasando por Francisco José Caldas hasta "los Caros, los Núñez, el gran bogotano Rafael Pombo; ... el dulce Jorge Isaacs con su bella María, ... y tantos otros que sería largo enumerar, joh, prolífica Colombia!" (6). Para Andrade Coello, la obra de Vargas Vila es uno de los escollos que impide "que esta regia nave no siga el triunfal rumbo que siempre le han impreso los capitanes del pensamiento, los pilotos de tu poesía, los genios de la gramática" (Andrade Coello 1912, 6). Vargas Vila no sólo está por fuera de esa tradición que Andrade Coello reconoce y celebra, sino que su mera presencia la amenaza. La idea de 'triunfal rumbo' remite a una noción de progreso, establecida desde ciertos orígenes - en este caso el mismo Bolívar como fundador del país literario-, y que implica el desarrollo de una concepción de las letras y de la nación asentada en ciertas convenciones del cómo decir y del qué decir.

La relación entre poder y lenguaje en la construcción de una idea de nación colombiana durante el siglo XIX ha sido ampliamente comentada en la obra de Malcolm D. Deas, Del poder y la gramática de 1993, en donde el historiador analiza la importancia del lenguaje en la consolidación de las élites de poder de la Colombia moderna, por medio de figuras como Rufino Cuervo y Miguel Antonio Caro. El partido Conservador, constituido a mediados del siglo XIX, protegía el lugar hegemónico de la doctrina católica en la cultura y sociedad colombiana y ha sido caracterizado históricamente como centralista e hispanista. Malcolm D. Deas asocia precisamente el interés de la clase intelectual conservadora por el estudio de la lengua, y la defensa de su pureza, con un proyecto político específico: "Me parece que el interés radicaba en que la lengua permitía la conexión con el pasado español, lo que definía la clase de república que estos humanistas querían" (Deas 2006, 47). Se establece entonces otro criterio de valoración de la obra literaria: además de que la dimensión moral del texto se ajuste a los parámetros de la doctrina católica, es necesario que también se apegue a los códigos del bien decir, basados en una visión hispanista del lenguaje. La obra de Vargas Vila no encaja en este proyecto, pero es lo suficientemente visible para no pasar desapercibida: si bien está condenada a un 'afuera' del canon nacional, no desaparece, sino que es un 'escollo' presente y actuante que tiene el poder de generar respuestas, como el estudio literario monográfico de Andrade Coello.

En el libro de Andrade Coello, gran parte de la crítica a la obra de Vargas Vila sigue efectuándose desde unas coordenadas morales: "El endiosamiento á la muerte, á la hipocresía, al vicio, al egoísmo no son capaces de existir en los albores de la juventud, ávida de ideales y de anhelos de vida" (71) y "Asustan las situaciones angustiosas en las que coloca a sus héroes, que son víctimas del vicio, ejemplares de placer" (66). Andrade Coello hace un juicioso recorrido por la bibliografía de Vargas Vila resumiendo y comentando un gran número de sus obras. La crítica a los valores -o antivalores - que atraviesa el libro va acompañada por un juicio al estilo. Para Andrade Coello, Vargas Vila se caracteriza por "su gramática bárbara" y empalagosa, llena de "esas palabras de relumbrón que no pertenecen ni a la lengua castellana, ese hacinamiento de adjetivos y de calificaciones a cada sustantivo y esos detestables adverbios que destrozan el oído por su interminable sonsonete en mente" (8). La existencia implícita de una presunta gramática 'no bárbara' y la crítica a los extranjerismos y neologismos dan cuenta de una concepción del lenguaje literario anclado en una tradición con reglas bien definidas desde donde Andrade Coello emite su juicio, que es además la concepción imperante en el campo literario del momento.

Este juicio estético al estilo nos remite al concepto de 'gusto' tal como lo presenta Raymond Williams: "Taste and 
Good Taste have become so separated from active human senses, and have become so much a matter of acquiring certain habits and rules..." (Williams 1983, 314). La crítica al estilo no es meramente una valoración estética natural, sino que es una construcción cultural enmarcada en un contexto socio histórico preciso. Vargas Vila, al alejarse de los parámetros estilísticos aceptados por su campo en su momento, se vuelve un escritor 'malo'. La tendencia de Vargas Vila de disentir, formalmente pero también moralmente, frente a los modos de decir y pensar hegemónicos es lo que lo convierte en un excéntrico.

A lo largo del libro de Andrade Coello se celebran ciertos aspectos de la escritura de Vargas Vila: la descripción de algún paisaje - "Conserva, al contrario, el encanto de algunas descripciones, como de las tardes otoñales de Bogotá, las agonías del sol detrás del Monserrate y el Guadalupe, las altiplanicies andinas, etc." (14) - , la construcción de un personaje - "Tremenda la pintura de Herodes y de Herodiada con sus abominaciones y sus crímenes. La aparición de Letia Serrano, mujer de alma, tiene toques vehementes" (51) - Esta posición aparentemente contradictoria reaparecerá en otros momentos de la crítica sobre Vargas Vila: existe un señalamiento generalizado al estilo vargasvilesco pero también se reconoce el vigor de su voz, a veces calificado como lleno de energía o sonoridad. En estos espacios coinciden momentáneamente la propuesta de Vargas Vila y las expectativas de lectura del crítico.

A pesar de la dureza con que Andrade Coello crítica la obra de Vargas Vila, el ecuatoriano no deja de reivindicarlo al final: "Al cerrar el libro, debo tributar un estrepitoso aplauso a Vargas Vila, por su elocuencia como tribuno revolucionario" (147). La obra de Vargas Vila, como escritor, periodista y editor, está repleta de críticas y denuncias al gobierno colombiano y a otros gobiernos de la región. Vargas Vila "se dedicó a combatir los gobiernos de Núñez, Holguines, Caro, Sanclemente, Marroquín, Reyes, Concha, Suárez, Ospina y Abadía Méndez de la 'república conservadora' de Colombia, y a déspotas sudamericanos como Estrada Cabrera, de Guatemala; Porfirio Díaz, de México, o Cipriano Castro, en Venezuela" (Alvarado Tenorio 2013). Vargas Vila también escribió vehemente en contra del gobierno estadounidense y de sus políticas intervencionistas, lo que lo llevo a ser señalado como "[t]he most violent of all the anti-Yankee group in the countries to the south" (Rippy 1922, 532). La posición combativa del escritor ante la tiranía es uno de los elementos, recurrente en la crítica posterior, que legitimaría parcialmente la figura de Vargas Vila.

\section{Éxito comercial: un lugar en la pirámide invertida}

En Las reglas del arte, Pierre Bourdieu estudia la relación entre el valor comercial de la obra y su capital cultural dentro del campo literario: "Estamos en efecto en un mundo económico al revés: el artista sólo puede triunfar en el ámbito simbólico perdiendo en el ámbito económico (por lo menos a corto plazo), y al contrario (por lo menos a largo plazo)" (Bourdieu 1955, 130). El éxito comercial es un criterio que invalida al autor ante la comunidad letrada, lo que establece una pirámide invertida de apreciación. La crítica que se efectúa sobre Vargas Vila condena que "casas editoriales poco escrupulosas propagan a destajo para redondear su negocio, atiborrando a la América española de producciones calenturientas en estilo bárbaro..." (Andrade Coello 1912, 10). Aquí se retoma la posición del cura Padrón de Guevara, en tanto que los editores y libreros ponen en marcha una estructura de producción y distribución de textos que no necesariamente se ajusta a las concepciones morales o estilísticas de la clase hegemónica. Estos libros son despojados de su valor literario, según la concepción de gusto construida por una minoría letrada y culta, pero no dejan de circular, ser leídos y discutidos, produciendo respuestas y polémicas que contribuyen a darle forma al campo.

En el caso de Vargas Vila, uno de los escritores más vendidos en Latinoamérica durante la primera mitad del siglo XX, la crítica señala constantemente su condición de autor popular y comercialmente exitoso. En un artículo que el profesor Arturo Torres-Rioseco escribe para Hispania con motivo de la muerte de Vargas Vila aparece tanto la noción de su éxito comercial - "Vargas Vila es acaso el único escritor de nuestra América que haya vivido de su pluma por más de cuarenta años" (Torres-Rioseco 1933, 400) - como la de su alcance: "Con todo, la brillantez extraordinaria de su estilo barroco, la vitalidad estupenda de su verbo, el brío en el ataque, lo rotundo de la negación dieron a sus libros una popularidad continental" (400). Su fama también creció en España, en donde vivió por varias temporadas. La popularidad de la propuesta literaria de Vargas Vila no estuvo limitada a su obra, sino que se reprodujo en las prácticas literarias de sus seguidores: "He aquí el secreto de que Vargas Vila sea más conocido de lo que merece. Sus imitadores - una juventud enfermiza que idolatra en las palabras sesquipedales y en la ilógica metáfora - son los enemigos más irreconciliables del idioma castellano y del sentido común" (Andrade Coello 1912, 11). A principios del siglo XX, el mercado del libro surge paralelo a una nueva clase media alfabetizada, con valores distintos a los de la élite. Ángel Rama habla de esta nueva clase en el proceso de modernización de las ciudades latinoamericanas: “... fue sin duda un campo autónomo respecto a la concentración del poder, como lo fue también la función educativa en la medida en que creció suficientemente como para no poder ser controlada rígidamente desde las esferas gubernamentales" (Rama 1988, 62). La emergencia de una comunidad lectora es lo que hace posible la presencia y la reproducción de una voz como la de Vargas Vila, tan dura e incómoda en su crítica a los dogmas, pero asentada firmemente gracias a su éxito comercial, lo que garantiza su visibilidad permanente.

Se abre paso a una crítica que sobrepasa los límites de la obra, como objeto literario, y de su valor estético y moral y se extiende al autor y a sus lectores. Torres-Rioseco acusa 
a Vargas Vila de que "cae en lamentables errores filosóficos y en aberraciones de manicomio" (399). Ecos de esta declaración aparecen ya en el texto de Ladrón de Guevara que lo tilda de "loco o endemoniado" (Ladrón de Guevara 1911, 448). Igualar las posiciones de Vargas Vila, sean políticas o morales, a la locura es un intento más de desautorizar discursivamente al escritor colombiano. Estas 'aberraciones de manicomio' obra de este 'loco' presuponen una distancia frente a una normalidad - no definida - que excluye a Vargas Vila. En esta cita extensa del texto de Torres-Rioseco se articulan distintas estrategias de deslegitimación:

José María Vargas Vila fue el ángel negro de la literatura hispanoamericana. Colombiano de origen, vagó por América y vivió en Europa la mayor parte de su vida. Formidable agitador de ideas revolucionarias elementales, sonoro demoledor de ídolos, enemigo eterno de toda forma de tiranía, Vargas Vila se fue demasiado tarde, cuando ya sus obuses se habían convertido en humildes arvejas y el fuego de sus cañones en luminarias de noche de navidad. Por muchos años fue el novelista predilecto de los literatos noveles de nuestro continente y más de un presidente de república hispanoamericana se inspiró en sus principios políticos. Rey de la metáfora, de la repetición, de la onomatopeya y de la barbarie gramatical, el escritor colombiano nos dejó unas cincuenta obras, de las cuales no salvará ni siquiera una página cuando el tiempo justiciero haga su recuento. (Torres Rioseco 1933, 399)

Cada elemento de la obra de Vargas Vila es desmontado por Torres-Rioseco: sus denuncias contra la tiranía han perdido poder y su gran audiencia no le garantiza un lugar en el canon, ni en la memoria literaria de la región. Javier Arango Ferrer, uno de los estudiosos más importantes de la literatura colombiana en el siglo XX, escribe en La literatura de Colombia que "Vargas Vila, como novelista tiene su clientela en el mundo camorrista y trasnochador que lee a Pedro Mata" (citado en Wade 1947, 474); en Horas de literatura colombiana diría que sus lectores están "en burdeles y pulperías" (Arango Ferrer 1978, 154); en Buenos Aires se dijo que era lectura para cocineras (Corral 1996, 269). Harold Alvarado Tenorio - poeta y editor colombiano-hace una extensiva recolección de las formas como fue estigmatizado: "sus numerosos enemigos, intelectuales al servicio de tiranos y autoritarios, lo llamaron bastardo, blasfemo, desnaturalizado, disolvente, pernicioso, mientras propagaban la especie de que vivía como un rey, era hermafrodita y homosexual, misógino, anarquista, terrorista e impotente" (Alvarado Tenorio 2013). Caracterizar a Vargas Vila como un simple loco, como una anomalía, y reducir a sus lectores a un espacio marginal es una estrategia violenta para removerlo del plano de las letras nacionales y continentales, es desestimar la naturaleza de sus diferencias y borrar toda causa justificada de su disenso. Los ataques de Vargas Vila no se han convertido en arvejas sólo por un exceso de retórica, como señalan sus detractores, sino porque la élite letrada, desde sus posiciones de poder en el campo, ha desplegado sus mecanismos discursivos una y otra vez para negarle cualquier posibilidad de potencia.

\section{La novela en la nación: espacios negados}

En 1947, Gerald E. Wade publicó el artículo "An Introduction to the Colombian Novel" en la revista Hispania. El artículo parte de la noción de que la novela colombiana no era lo suficientemente conocida fuera de Colombia, con excepción de María, La Vorágine y tal vez un par de obras más. Para Wade esta ausencia no era necesariamente una cuestión de falta de merecimiento, sino por el enfoque primordial de los críticos colombianos en la producción poética que había dejado reducida a la novela, según su lógica, a un género menor. Raymond Leslie Williams, quien en 1991 publicó The Colombian Novel. 1844-1987, planteó este conflicto desde la perspectiva de la lucha de partidos políticos - Liberal y Conservador - que atravesó la historia del poder en Colombia durante la mayor parte del siglo XX. Las diferencias ideológicas entre los dos partidos han sido una constante en los debates de la producción literaria que le dieron forma al campo: "Whereas Colombian novelists have tended to be Liberals, its literary critics have been mostly Conservatives. Recognizing this situation can help explain why Colombian novelists have always claimed the nation has no critics, while the critics have sustained that Colombia has no novelists." (Williams, Raymond Leslie 1991, 23). Vargas Vila, como militante del partido Liberal, participó en las guerras civiles de finales del siglo XIX; fue precisamente la derrota de las tropas liberales lo que lo llevarían a su exilio a Venezuela. Para Wade, Vargas Vila es un "extravagant genius" (Wade 1947, 474) que publicó desde Barcelona, Madrid, París, Roma, La Habana y México. La posibilidad de desarrollar una extendida producción novelística se vio determinada por su condición de expatriado: “...his novels, one suspects strongly, could not find a Colombian publisher, for their contents have been deplored by all Colombian critics whose remarks on his art I have been able to find" (Wade 1947, 474). De acuerdo a Wade, Vargas Vila no pudo publicar sus novelas en Colombia tanto por el lugar secundario del género dentro del campo, como por el contenido de las mismas, ya que iban en contravía de los valores partidistas y políticos de las élites culturales. La noción de Wade no da cuenta de las operaciones violentas que terminan por determinar su ausencia: no es el simple hecho de la inexistencia de editoriales dispuestas a publicar a Vargas Vila, sino que su ausencia es consecuencia de un enfrentamiento, que incluso se manifiesta en un contexto bélico determinado, entre nociones distintas de nación y de literatura. Las élites literarias que rechazan a Vargas Vila lo hacían para proteger un sistema de valores que perpetuaba ciertas relaciones sociales: "Literature was performing several functions by the early twentieth Century, but the novels that received official acceptance functioned as moral ideology" (Williams, Raymond Leslie 1991, 43). La élite letrada colombiana no 
sólo dejó de abrir un espacio para Vargas Vila, una manera de resistencia pasiva incrustada en las estructuras vigentes, sino que también se encargó activamente de convertirlo en una figura estigmatizada y prohibida.

Los textos de Vargas Vila, quien para Wade era "a sort of literary black sheep" (Wade 1947, 474), también resultaban difíciles de ubicar con precisión dentro de las convenciones de géneros. Wade nos dice que Vargas Vila publicó alrededor de doce novelas: "At least they are novels if one broadens the term" (Wade 1947, 474). La crítica señala recurrentemente la rareza en el tipo de narraciones que comprenden la obra de Vargas Vila: allí aparecen tragedias de cinco actos que no deben ser actuadas y obras históricas con grandes licencias literarias, entre otras. Muchos de estos textos se resisten a ser encasillados dentro del marco de las convenciones genéricas tradicionales. A lo largo de toda la crítica sobre Vargas Vila aparecen caracterizaciones como "escritor atípico, inclasificable" (Knight 2001, 24). Para Wade el interés que puede despertar Vargas Vila radica precisamente en esa posición extrema: "The bolder reader may want to investigate him as an example of one of the more extravagant turns which the human spirit can take in its iconoclastic yearnings toward emancipation from the conventional in human thought and living" (Wade 1947, 475). Leer a Vargas Vila solamente desde su rareza, desde su monstruosidad, es ignorar las tensiones políticas y literarias que continuamente lo han empujado allí.

Germán Arciniegas, historiador colombiano, también caracterizado por su lucha en contra de la oligarquía colombiana y las dictaduras latinoamericanas, fue el encargado de escribir el prólogo a una edición de 1984 de cuatro novelas de Vargas Vilas para la editorial Círculo de Lectores. Arciniegas habla sobre su acercamiento a la obra de Vargas Vila como lector: "Vargas Vila era uno de los que no podían leerse. Estaba prohibido" (Arciniegas 1984, I). La prohibición, en el contexto de una sociedad aún gobernada por unos valores religiosos, afectaba el acceso a los textos; las únicas librerías donde se conseguían eran las liberales. "Con todo, eran irresistibles como tentación sus libros panfletarios" (Arciniegas 1984, II). Acceder al objeto libro era una forma de establecer pertenencia a un grupo social que se oponía al conservadurismo político y literario. Más allá del valor comercial, lo que se señala es su valor simbólico. Los lectores de Vargas Vila de los que habla Arciniegas, no son el mismo público estigmatizado por la crítica, sino que se trata de una nueva clase intelectual dispuesta a redefinir las maneras de hacer y decir en Colombia. Nos dice Arciniegas que "[e]ntre las jóvenes colombianas, Vargas Vila, por inmoral, se leía en secreto. Pero se leía" (Arciniegas 1984, II). El gesto de Vargas Vila, al escribir en contra de los dogmas cristianos y su doble moral, se reproduce en el gesto subversivo del lector o de la lectora de pasar por alto la prohibición. En el texto de Arciniegas, el desplazamiento de la figura del autor como objeto de discordia hacia la materialidad de sus libros, permite reivindicar al público de Vargas Vila. Arci- niegas también nos cuenta la visita a un amigo escritor que trabajaba en la cárcel:

Voy a presentarte un caso singular: un condenado por el asesinato de un compañero en Girardot. Los dos, bogas del Magdalena. Se trabó entre ellos un alegato a muerte: el homicida sostenía que Vargas Vila era el mejor escritor del mundo. El otro decía que Víctor Hugo. Londoño preguntó al recluso: Dime cómo ocurrieron las cosas... Vea doctor: no crea que era cuestión de tragos. Yo no había tomado y estaba en mi sano juicio. Pero lo que son las malas. Se le ocurre a ese desgraciado decirme que Víctor Hugo era mejor que Vargas Vila. ¿Se da cuenta, doctor? Y explicando así las cosas fue exaltándose hasta decir: ¡Si otra vez se me presentara, pues lo mato, carajo! (Arciniegas 1984, II).

La anécdota, por supuesto, le puede dar la razón a aquellos que representan a los lectores de Vargas Vila como criminales, pero también da cuenta del lugar que Vargas Vila ocupó en Colombia: existía en el país una comunidad de lectores leales para quienes su literatura sí era válida. Arciniegas sigue explorando el vínculo entre Vargas Vila y Víctor Hugo, incluyendo un comentario atribuido a Anatole France: "A este hombre, Vargas Vila, flor medrosa de la lejana Colombia, no le falta más que una cosa para sentarse a la diestra de nuestro padre Hugo: Haber nacido en Francia" (Arciniegas 1984, III). Vargas Vila no encaja en la tradición literaria colombiana del momento, donde, en palabras de Andrade Coello, no es más que un mero escollo; así que no se puede reclamar allí su genealogía para autorizarlo. Arciniegas establece un vínculo entre el criticado estilo vargasvilesco y sus influencias europeas: "Sobre la excesiva carga retórica que se encuentra en Vargas Vila no hay que olvidar que venía de fuera. Por eso se habla tanto de lo victorhuguesco o dannunziano en Vargas Vila" (Arciniegas 1984, IV). Es necesario recurrir a una genealogía por fuera de Colombia para autorizar a un escritor proscrito, que escribe en contravía de las élites letradas que controlan los mecanismos de reproducción y canonización en el campo nacional.

\section{Vargas Vila, hoy.}

A pesar de los esfuerzos de parte de la élite letrada por desautorizar a Vargas Vila, su figura no se olvida. Revisar la presencia de Vargas Vila en la actualidad nos lleva a encontrarnos con dos posturas bien diferenciadas. Por un lado, reaparecen juicios que buscan mantener a Vargas Vila afuera de los límites de la 'alta' literatura. En la reseña del 2000 del diario de Vargas Vila, el crítico mexicano Christopher Domínguez Michael escribió: "El desprecio de la posteridad por José María Vargas Vila (1860-1933) es unánime" (Domínguez Michael 2000). Por supuesto, tal unanimidad existe más en el deseo del comentarista que en el mundo literario, siendo el texto reseñado, Diario (de 1899 a 1932) y la increíble historia de unas memorias codiciadas, la prueba 
misma de su error [2]. Domínguez Michael recoge otro de los temas recurrentes de la crítica sobre el autor: "Vargas Vila lo tuvo todo y todo lo derrochó. Ese fue su heroico y colosal fracaso". Vargas Vila tenía el capital cultural para producir obras que se ajustaran a la definición de literatura que la crítica promulgaba:

Vargas Vila, autor de novelas sicalípticas, fue un hombre culto. Pero su formación clásica y sus lecturas románticas — no sólo Lamartine, Vigny y Chateaubriand, también Joseph de Maistre y Bonald - fueron a dar a un anchuroso Amazonas de la cursilería, como barquitos de papel que delatan la extenuante travesía de las literaturas americanas hacia el talento individual. (Domínguez Michael 2000).

El tema del desperdicio está presente desde la crítica de Andrade Coello: "Desperdicia su talento, que ha producido chispazos deslumbrantes, en esfuerzos que no son para bien de la humanidad; en apasionamientos sectarios, en futilezas de nimiedad desesperante" (Andrade Coello 1912, 7). Vargas Vila tiene el conocimiento necesario para escribir bien: "Vargas Vila knows thoroughly the resources of the language, although some of his critics do not approve of the way he uses them" (Wade 1947, 475). Desperdiciar significa no darle a algo su uso adecuado; en tanto a la capacidad literaria de un autor, significa poner el conocimiento, el conjunto de saberes necesarios que nos autoriza, a un uso supuesto. Hablar de usos adecuados o supuestos de los saberes del quehacer literario nos remite nuevamente a la idea de una normalidad, que no es más que una mera convención del campo literario en un momento determinado. Vargas Vila no escribe 'mal' porque carece de las herramientas y los saberes para escribir 'bien', sino porque quiere cuestionar abiertamente lo que consensualmente se ha establecido como 'escribir bien' en el contexto de la literatura colombiana y latinoamericana.

Respecto al Diario (de 1899 a 1932) y la increíble historia de unas memorias codiciadas, Efrin Knight, quien preparó otra edición, escribió: "Esperemos que esta nueva publicación inspire una reedición de sus novelas más famosas, así como la de algunos de sus libros de pensamientos, muchos de los cuales son aún de actualidad" (Knight 2001, 30). Knight convoca a una resurrección de Vargas Vila, "injustamente olvidado", reivindicando sus facetas anticlerical y antiamericana - antiestadounidense - y su lucha por la libertad. Su llamado, en contravía a muchas de las apreciaciones históricas sobre el escritor colombiano, no es sólo a revisar su figura sino también su obra, que no ha perdido vigencia.

La publicación de la novela La semilla de la ira en el 2008 por parte de la editorial Planeta Colombia es una evidencia más de que Vargas Vila no ha sido olvidado. La autora de la novela, Consuelo Triviño Anzola, había escri- to su tesis doctoral sobre el mismo autor y preparado una edición de su diario. Desde el campo académico y el campo literario, Triviño Anzola hace visible una vez más a 'el Divino', como se le conocía a Vargas Vila. La novela narra la vida de Vargas Vila desde 1899 hasta 1933, desde el punto de vista del escritor, reproduciendo un estilo Modernista. Convertir a Vargas Vila en el narrador le permite a la autora revisitar su historia, así como justificar sus luchas. La novela está llena de frases en donde la voz reflexiona sobre su lugar en el mundo literario y político hispanoamericano: "Mi vida se resume en una lucha sin tregua por derruir el reinado ignomioso de la mentira, por una imperiosa necesidad de gritarle al mundo las verdades que nadie se atreve a afrontar" (Triviño 2008. 57). La novela ha brindado la oportunidad, una vez más, de volver a hablar sobre Vargas Vila. Reseñas en medios como "El País" de España vuelvan a hacerlo visible. Escritores colombianos han revisitado su figura y su obra, problematizando varios de los juicios que tradicionalmente se le han concedido. En el periódico El Tiempo, Harold Alvarado Tenorio revisita la figura de Vargas Vila con una intención decididamente reivindicatoria:

Nadie como él [...] hizo que las ideas y las maneras de ver el mundo de artistas y pensadores laicos ascendieran hasta las voluntades de millares de intelectuales campesinos, jornaleros, analfabetos, desposeídos y desocupados que aspiraban a ser tan libres como Jorge Amado, Pablo Neruda, Gabriela Mistral, Jorge Luis Borges, Alejo Carpentier, Guillermo Cabrera Infante, José Vasconcelos, Francisco Umbral, Ramón Gómez de la Serna, Gabriel García Márquez, José Donoso, Jorge Zalamea o Ramón del Valle Inclán, ese puñado de sus admiradores, que reconocieron que sin él y sin su prosa no habrían existido.

Señalar su legado en autores canónicos latinoamericanos es una estrategia de validación, a la vez que redefine la visión existente sobre quiénes eran sus lectores. Su audiencia no es la periferia moral, criminales y pecadores, sino una periferia social: los excluidos por el sistema de valores y relaciones que la oligarquía protege de la prosa de Vargas Vila. Alvarado Tenorio reivindica el estilo de Vargas Vila, estableciendo una relación entre el objeto estético y la posición moral del autor:

Una prosa lírica cuya eficacia no hay que buscar entre las sábanas, sino en su fluir subversivo contra lo establecido, los discursos oficiales hegemónicos cuyos designios nacionales se sustentan en nociones como la familia burguesa, las tutelas morales de las iglesias y la centralización de los poderes que explotan, excluyen y reprimen el cuerpo social y el individuo (Alvarado Tenorio 2013).

Si Vargas Vila va a escribir mal - en contra de las instituciones sociales que violentan a la sociedad colombiana de 
principios del siglo XX-, se va a asegurar que en la cualidad estética de su escritura se refleje ese descontento.

La edición de julio y septiembre del 2015 de la Revista Iberoamericana, órgano del Instituto Internacional de Literatura Iberoamericana con sede en Pittsburgh, Estados Unidos, fue dedicada a Vargas Vila bajo la coordinación de Juan Carlos González Espitia y María A. Salgado. En el texto introductorio "Vargas Vila, más allá de la hipérbole", los editores parten del carácter de figura polémica del autor y de las lecturas parciales producto de su actitud polarizante: "La tensión entre obra y autor, entre conseja y textualidad, entre admiración acrítica y odio enconado nos deja, a ciento cincuenta años de su nacimiento, con un Vargas Vila inusitadamente vivo pero al mismo tiempo con un Vargas Vila infortunadamente nebuloso" (González Espitia et al. 2015, 725). Que una revista reconocida en el campo de los estudios literarios latinoamericanos abra un espacio para Vargas Vila, demuestra no sólo su vigencia, sino lo posibilidad, y necesidad, de un productivo estudio de su obra en el ámbito académico:

Parece entonces que hace falta leer más y mejor a Vargas Vila, forjar una herramienta que corte y que punce en el tejido de su obra, pero con mayor certeza, mejor dicho, con mayor justicia. Leer críticamente, quizás por primera vez, sin prevenciones positivas o negativas, los textos menos conocidos de su producción. El resultado de este tipo de labor mesurada y responsable será muy posiblemente uno que nos enseñe a Vargas Vila como productor literario, no como divino o como humano, para usar la que es ya una fórmula para referirse a él. (González Espitia et al. 2015, 727).

Por un lado, algunos de los artículos de la edición hacen un análisis de los recursos literarios que aparecen en obras específicas de Vargas Vila u ofrecen lecturas paralelas a otras figuras literarias reconocidas - como José Eustasio Rivera y Fernando Vallejo- mientras que otros iteran la excepcionalidad de su vida y su posición dentro de un nuevo paradigma de intelectual. Consuelo Triviño Anzola, en "Vargas Vila, del mito y la leyenda a la ficción narrativa", reitera ese carácter mítico ligado a la vida del hombre: "Más allá de la validez de algunos de sus textos, lo verdaderamente significativo es el fenómeno social, el mito de Vargas Vila en el imaginario latinoamericano, desde México hasta Argentina, que exige ser tenido en cuenta." (Triviño Anzola 2015, 829). Es decir, aún dentro del análisis académico, no se resuelve la tensión entre el ejercicio de valoración de los contenidos literarios de la obra y la mitificación de su biografía.

\section{Conclusión}

La figura de Vargas Vila parece haber sido restituida una vez más de su valor simbólico. Ese valor ha sido arrebatado una y otra vez, desde sus múltiples desplazamientos transnacionales forzados por sus posturas políticas, desde los diversos aparatos críticos que han juzgado su obra como excesiva o insuficiente, desde los juicios morales del conservadurismo y desde la estigmatización constante del autor y de su audiencia. Aún así, muchos de los prejuicios que la historiografía literaria ha construido alrededor de su figura continúan actuando en la forma en que es leído. Si bien coincido con la propuesta de Juan Carlos González Espitia y María A. Salgado, que invita a volver la mirada crítica a la obra del escritor, de "leer más y mejor" su producción literaria, es imperante leerla a contrapelo de las operaciones del campo que luchó por borrarlo.

Reivindicar a Vargas Vila políticamente por su posición determinante como una figura de disenso en contra de las élites del poder americano no es suficiente. Es necesario encontrar las técnicas en las cuales ese disenso está presentes dentro su proyecto estético. Estas luchas en contra de la tiranía y los dogmas están imbuidas en su lenguaje "bárbaro", en su desprecio por una gramática normalizada y normativa, presente en el uso de extranjerismos y neologismos, así como en la innovación, o desprecio, de las convenciones de los géneros literarios. La valoración de su obra debe dar cuenta del desfase de su escritura con las nociones de gusto de su momento e incluso del nuestro.

El éxito comercial de Vargas Vila está ligado a la emergencia de un público lector que se identificaba con su molestia frente a instituciones y prácticas excluyentes que favorecían el poder político y cultural de una minoría letrada. Valorar o no el estilo de Vargas Vila se convirtió a su vez en una medida para definir la posición del lector dentro del campo cultural. Como se ha mostrado a lo largo de este trabajo, la crítica extiende el desprecio por el autor a un desprecio por sus lectores: o se era heredero de una escuela del Gusto sostenida por una tradición o se hablaba desde el desconocimiento de esos valores, desde una acusada ignorancia. Vargas Vila es el punto donde chocan dos visiones de lo literario: el de la crítica que defiende las nociones del buen decir y el de una audiencia emergente que no se siente representada por esos códigos. Es por eso que la obra de Vargas Vila se debe enmarcar en un conflicto más amplio en el que se redefinan las prácticas de escritura y de lectura, de las que el mero análisis de su obra basado en criterios meramente estéticos no da cuenta. Leer a Vargas Vila solamente desde su monstruosidad, desde su extravagancia, es perpetuar los mecanismos de exclusión de una clase hegemónica que desautoriza a quien la cuestiona, es negar las violencias que reducen y estigmatizan aquello que encuentra incómodo. Pero normalizar a Vargas Vila, otorgarle un lugar mítico dentro del canon, al lado de aquellos a quienes criticó, sería arrebatarle su vigor y despojarlo de todo aquello que lo caracterizó. La figura de Vargas Vila existe en la periferia, fuera pero aún parte de; es necesario leerlo desde allí, donde 
se hacen evidentes las tensiones y los conflictos en esa animada contienda sobre la definición de sus ideas de nación, de libertad y de literatura.

\section{Notas}

1. La conflictiva historia de Vargas Vila con la Iglesia es anecdótica e ideológica: ya desde su juventud se enfrentó a las autoridades religiosas, denunciando a curas directamente, lo que lo llevó incluso a perder su empleo y ser excomulgado. Fue crítico de la relación entre Iglesia y Estado en Colombia, especialmente después de la llegada de Rafael Núñez al poder, y siempre se pronunció en contra de los privilegios del clero.

2. Diario (de 1899 a 1932) y la increíble historia de unas memorias codiciadas fue publicado por Ediciones Altera en Barcelona en el 2000. Efrin Knight habla de una edición más completa, preparada en Miami por la hoy desaparecida Editorial Arenas. Existe también una versión llamada Diario Secreto, cuya selección y notas fueron hechas por Consuelo Triviño y fue publicado en Bogotá en 1989.

3.

\section{Obras citadas}

Andrade Coello, Alejandro. 1912. Vargas Vila. Ojeada crítica de sus obras: De "Aura o las violetas" a "El ritmo de la vida". Quito: s. n.

Alvarado Tenorio, Harold. 2013. "80 años sin Vargas Vila, el más temido de los panfletarios colombianos”. El Tiempo.com. Consultado el 27 de octubre del 2017. http://www.eltiempo.com/archivo/documento/CMS-12912371.

Arango Ferrer, Javier. 1978. Horas de literatura colombiana. Bogotá: Instituto Colombiano de Cultura.

Arciniegas, Germán. 1984. Prólogo. En Aura o las violetas. Emma. Lo irreparable. Flor de fango. Bogotá: Círculo de lectores.

Bourdieu, Pierre. 1955. Las reglas del arte. Génesis y estructura del campo literario. Barcelona: Editorial Anagrama.

Corral, Wilfrido H. 1996. "Nuevos raros, locos, locas, ex-céntricos, periféricos y la historia literaria del canon de la forma novelística”. Revista hispánica Moderna 2 (49): 267-284.

Domínguez Michael, Christopher. 2000. “Diario (de 1899 a 1932) y la increíble historia de unas memorias codiciadas', de José María Vargas Vila". Letraslibres.com. Consultado el 27 de octubre del 2017. http://www.letraslibres.com/mexico/libros/diario-1899-1932-y-la-increible-historia-unas-memorias-codiciadas-josac-mara-vargas-vila.

Deas, Malcolm D. 1993. Del poder y la gramática y otros ensayos sobre historia, política y literatura colombianas. Bogotá: Tercer mundo editores.

González Espitia, Juan Carlos, y María A. Salgado. 2015. "Vargas Vila, más allá de la hipérbole". Revista Iberoamericana 252 (81): 723-727.

Ladrón de Guevara, P. Pablo. 1911. Novelistas malos y buenos. Bilbao: La Editorial Vizcaína.

Knight, Efrin. 2001. “¿Una futura resurrección?: El Diario de Vargas Vila”. Revista de Humanidades: Tecnológico de Monterrey 11. 21-31.

Rama, Ángel. 1998. La ciudad letrada. Montevideo: Arca.

Rippy , J. Fredd. 1922. "Literary Yankeephobia in Hispanic America.” The Journal of International Relations, 4 (12). 524-538.

Torres-Rioseco, Arturo. 1933. "Francisco Contreras y Vargas Vila”. Hispania 4 (16). 399-400.

Triviño Anzola, Consuelo. 2008. La semilla de la ira. Bogotá: Editorial Planeta Colombiana.

Triviño Anzola, Consuelo. 2015. "Vargas Vila, del mito y la leyenda a la ficción narrativa". Revista Iberoamericana 252 (81): 827-835.

Wade, Gerald E. 1947. "An Introduction to the Colombian Novel." Hispania 30 (4). 647-483.

Williams, Raymond. 1983. Keywords. A Vocabulary of Culture and Society. New York: Oxford University Press.

Williams, Raymond Leslie. 1991. The Colombian Novel, 1844-1987. Austin: University of Texas Press. 